\title{
Solar diameter observations at Observatório Nacional in 1998-1999
}

\author{
S. Puliaev ${ }^{1,2}$, J.L. Penna ${ }^{1}$, E.G. Jilinski ${ }^{1,2}$, and A.H. Andrei ${ }^{1}$ \\ 1 Observatório Nacional/CNPq, Brasil \\ 2 Pulkovo Observatory, Russia
}

Received September 2, 1999; accepted February 3, 2000

\begin{abstract}
In January 1997, at the Observatório Nacional (ON), Rio de Janeiro, Brazil, digital CCD observations of the solar diameter began with a Danjon astrolabe adapted for solar observations and equipped with a variable angle reflecting prism. The prism enables observations of the Sun several times per day and all year round at the southern latitude $\varphi=-22^{\circ} 54^{\prime}$.

As of June 1999, about 9000 observations have been made. The mean value of the apparent semi-diameter is $959 .^{\prime \prime} 13 \pm 0$.' 01 .

Here we report on the results obtained between July 1998 and June 1999. In 162 days 4276 observations were made. For this period the mean apparent semi-diameter is $959 . \prime 07 \pm 0$. .'02. No significant difference between the apparent semi-diameters is found as observed on the East and West sides of the meridian.

The results of the observations are updated every month and available in electronic form in the SIMBAD database and at the World Wide Web page of the ON, Solar Radius Data: http://obsn.on.br/radius/.
\end{abstract}

Key words: Sun: general, fundamental parameters

\section{Introduction}

The program for solar CCD observations with a Danjon astrolabe, aiming to monitoring variations of the apparent diameter, has been pursued since January 1997 at the Observatório Nacional (ON), Rio de Janeiro $(\varphi=$ $\left.-22^{\circ} 54^{\prime}\right)$. First results and analysis of the observations through June 1998 were reported in Jilinski et al. (1998, 1999).

Send offprint requests to: S. Puliaev, Observatório Nacional/CNPq, R. Gal. José Cristino 77, CEP20921400, Rio de Janeiro, Brasil.

e-mail: puliaev@on.br
Here the results of the campaign from July 1998 to June 1999 are presented. Analogous studies have been made by Noël $(1995,1998)$ and Laclare (1996).

The observations have been made with a reflecting variable angle prism, between $27^{\circ}$ and $58^{\circ}$ of zenith distance. A description of the observational method used is given in Chollet \& Sinceac (1999).

The images of the Sun are acquired by a CCD camera COHU \# 4710. The camera is IR sensitive (4000$10000 \AA$ ). The effective wavelength is $6400 \AA$ and the bandpass is $3000 \AA$.

\section{Results and discussion}

Table 1 gives annual statistics of the observations for the whole observational period. Notice that the errors of the mean daily value of the semi-diameter $\sigma_{\text {day }}$ and the error of single observations $\sigma_{1}$, became smaller in 1998 and 1999, than in 1997. This was due to a narrower observation bandpass and to improvements in the observational routine.

Normally, about 20 or more (up to 30) observations, on each side of the Sun's meridian cross are made in summer months. These figures fall to about 10 or less, on each side, in June when the Sun is comparatively low above the horizon. The Summer months, from December to February, are mostly rainy, resulting in less effective observing time than in the Winter, from June to August, but many more diameter measurements.

For the one-year period here considered there are 162 days of observation. In spite of the hard weather conditions of the observations, the astrolabe performed rather stably. No dependence was found of the observed semidiameter on time length of observations (that vary from 2 to 7 minutes) and azimuth.

An analysis of the apparent semi-diameter and some studies concerning the variation of the astroclimatic conditions at $\mathrm{ON}$ are in preparation. Here instead we focus on the monthly average values, whose distribution is approximately normal. 
Table 1. Mean values of apparent Sun semi-diameter and errors (in arcsec) for the years 1997, 1998 and from January to June 1999. The Day column displays the number of observational days during the year, Obs brings the total number of observations, Diam - the mean semi-diameter, $\varepsilon$ - its error, $\sigma_{\text {day }}$ - the error of mean daily value of semi-diameter and $\sigma_{1}$ - the error of a single observations

\begin{tabular}{|c|c|c|c|c|c|c|c|c|c|c|c|c|c|c|c|c|c|c|}
\hline & \multicolumn{6}{|c|}{ East transits } & \multicolumn{6}{|c|}{ West transits } & \multicolumn{6}{|c|}{ All transits } \\
\hline Year & Day & Obs & Diam & $\varepsilon$ & $\sigma_{\text {day }}$ & $\sigma_{1}$ & Day & Obs & Diam & $\varepsilon$ & $\sigma_{\text {day }}$ & $\sigma_{1}$ & Day & Obs & Diam & $\varepsilon$ & $\sigma_{\text {day }}$ & $\sigma_{1}$ \\
\hline 1997 & 144 & 1854 & $959.25 \pm$ & .03 & .20 & .60 & 69 & 802 & $959.32 \pm$ & .06 & .22 & .69 & 158 & 2656 & $959.27 \pm$ & .03 & .20 & .63 \\
\hline 1998 & 135 & 1873 & $959.17 \pm$ & .02 & .14 & .46 & 140 & 2044 & $959.07 \pm$ & .02 & .13 & .44 & 162 & 3917 & $959.12=$ & .02 & .14 & .45 \\
\hline 99 Jan.-June & 70 & 1125 & $958.93 \pm$ & .03 & .15 & .53 & 73 & 1154 & $958.96 \pm$ & .02 & .12 & .42 & 84 & 2279 & $958.95 \pm$ & .02 & .13 & .47 \\
\hline All period & 349 & 4852 & $959.15 \pm$ & .02 & .17 & .54 & 282 & 4000 & $959.10 \pm$ & .02 & .15 & .49 & 404 & 8852 & $959.13 \pm$ & .01 & .16 & .52 \\
\hline
\end{tabular}

Table 2. Monthly average apparent semi-diameters (in arcsec) from July 1998 to June 1999. The Day column displays the number of observational days during the month, the Obs column brings the total number of observations. Columns Diam and $\varepsilon$ bring the mean semi-diameter and rms error

\begin{tabular}{|c|c|c|c|c|c|c|c|c|c|c|c|}
\hline \multirow[b]{2}{*}{ Month } & \multicolumn{4}{|c|}{ East transits } & \multicolumn{4}{|c|}{ West transits } & \multicolumn{3}{|c|}{ All transits } \\
\hline & Day & Obs & Diam & $\varepsilon$ & Day & Obs & Diam & $\varepsilon$ & Day & Obs & Diam \\
\hline July 1998 & 14 & 127 & $959.33 \pm$ & 0.10 & 16 & 187 & $959.12 \pm$ & 0.04 & 17 & 314 & $959.22 \pm 0.05$ \\
\hline August & 13 & 194 & $959.15 \pm$ & 0.09 & 13 & 217 & $959.08 \pm$ & 0.04 & 14 & 411 & $959.11 \pm 0.05$ \\
\hline September & 9 & 126 & $959.12 \pm$ & 0.05 & 12 & 212 & $959.08 \pm$ & 0.05 & 13 & 338 & $959.10 \pm 0.03$ \\
\hline October & 6 & 82 & $959.13 \pm$ & 0.08 & 8 & 145 & $959.12 \pm$ & 0.10 & 9 & 227 & $959.12 \pm 0.07$ \\
\hline November & 8 & 159 & $959.28 \pm$ & 0.06 & 10 & 184 & $959.14 \pm$ & 0.06 & 11 & 343 & $959.20 \pm 0.04$ \\
\hline December & 11 & 175 & $959.45 \pm$ & 0.06 & 12 & 189 & $959.34 \pm$ & 0.05 & 14 & 364 & $959.39 \pm 0.03$ \\
\hline January 1999 & 13 & 224 & $959.06 \pm$ & 0.08 & 13 & 224 & $959.16 \pm$ & 0.04 & 15 & 448 & $959.11 \pm 0.04$ \\
\hline February & 10 & 219 & $958.78 \pm$ & 0.04 & 12 & 189 & $958.85 \pm$ & 0.05 & 13 & 408 & $958.82 \pm 0.03$ \\
\hline March & 14 & 257 & $958.88 \pm$ & 0.06 & 12 & 217 & $958.94 \pm$ & 0.03 & 16 & 474 & $958.91 \pm 0.04$ \\
\hline April & 14 & 217 & $958.88 \pm$ & 0.06 & 13 & 237 & $958.83 \pm$ & 0.06 & 15 & 454 & $958.86 \pm 0.04$ \\
\hline May & 9 & 116 & $958.07 \pm$ & 0.13 & 13 & 181 & $959.02 \pm$ & 0.05 & 14 & 297 & $959.00 \pm 0.05$ \\
\hline June & 10 & 92 & $959.04 \pm$ & 0.10 & 10 & 107 & $958.94 \pm$ & 0.06 & 11 & 199 & $958.99 \pm 0.06$ \\
\hline All period & 131 & 1988 & $959.08 \pm$ & 0.03 & 144 & 2288 & $959.05 \pm$ & 0.02 & 162 & 4276 & $959.07 \pm 0.02$ \\
\hline
\end{tabular}

In Table 2 are presented the number of the days of observation, the total number of observations during a month and the monthly averages. The results of the East and West observations are tabulated as well as an average of all transits.

The error of a single measurement of the solar semidiameter for the period of 1998-1999 is $0^{\prime \prime} .51$ for the East and 0 "' 43 for West observations.

Table 1 indicates a decreasing trend of 0 ' 16 per year for the apparent semi-diameter. The average value for 1998.25 is $9599^{\prime \prime} 13$. This represents a difference of $0{ }^{\prime \prime} 4$ for the average value of Calern observations for the period $1975-1998$ (Laclare et al. 1999a, 1999b). However, similar trends and differences can also be found within the Calern series. On the other hand, discrepancies in the average values can be expected due to differences in the effective observational wavelength, in the operating definition of the solar border and in the prevailing local atmospheric conditions.

Complete results of the daily series are updated every month and can be retrieved in electronic form from the SIMBAD database and from the homepage of $\mathrm{ON}$ (http://obsn.on.br/radius/). For the electronic form, the daily data are given: the number of observations, the semidiameter mean value, its rms error, the date in format YYMMDD, the Modified Julian Date and the error of a single observation.

\section{Conclusions}

4276 digital CCD observations of the solar diameter during 12 months from July 1998 to June 1999 were made. The mean apparent semi-diameter is $959 !^{\prime \prime} 07 \pm 0{ }^{\prime \prime} 02$. The difference between mean East and West apparent semidiameters is $0 . \prime 03$, which is non significant face the measurements errors.

Since 1997 near 9000 observations have been made. The mean value of the apparent semi-diameter for the entire series is $959 .^{\prime \prime} 13 \pm 0^{\prime \prime} 01$.

The error of a single observation of semi-diameter for the period of 1998-1999 is 0 ". 51 for the East and 0". 43 for West observations. The standard error of the daily mean observed semi-diameter is 0 "' 14 .

Further observations are highly desirable to study the measured variations in time of the solar semi-diameter. 
Acknowledgements. This work was partially supported by the $\mathrm{CNPq} /$ Brazil - CNRS/France binational agreement No. 910172/95-1. S.P. and E.G.J. thank CNPq/Brazil for the financial support under the contracts 300016/93-0 and 300017/93-6. This work was partially supported by FAPERJ.

\section{References}

Chollet F., Sinceac V., 1999, A\&AS 139, 219

Jilinski E.G., Puliaev S.P., Penna J.L., et al., 1998, A\&AS 130, $1-10$
Jilinski E.G., Puliaev S.P., Penna J.L., Andrei A.H., Laclare F., 1999, A\&AS 135, 227-229

Laclare F., Delmas C., Coin J.P., Irbah A., 1996, Solar Phys. 166, 211-229

Laclare F., Delmas C., Sinceac V., Chollet F., 1999a, C.R. Acad. Sci. Paris, t.327, Série II b, pp. 645-652

Laclare F., Delmas C., Irbah A., 1999b, C.R. Acad. Sci. Paris, t.327, Série II b, pp. 1107-1114

Noël F., 1995, A\&AS 113, 131-132

Noël F., 1998, A\&AS 132, 195-196 